\title{
O (não) lugar do reflexo no modo causal de seleção pelas consequências de Skinner
}

\author{
Marcus Bentes de Carvalho Neto \\ Universidade Federal do Pará (UFPA) \\ Thais Maria Monteiro Guimarães \\ Universidade Federal do Pará (UFPA) \\ Alejandra Rodríguez Sarmiento \\ Universidade Federal do Pará (UFPA) \\ Monalisa de Fátima Freitas Carneiro Leão \\ Universidade Federal do Pará (UFPA) ${ }^{1}$
}

\begin{abstract}
RESUMO
Skinner em 1981 propôs um modo causal geral para explicar o comportamento envolvendo dois processos básicos e complementares: variação e seleção. Algumas vezes o selecionismo é apresentado como um substituto do mecanicismo dentro e fora do âmbito comportamental. Contudo, há um ponto de tensão nessa interpretação: o comportamento/condicionamento reflexo. Esse tipo de comportamento e de aprendizagem seria explicado através de leis compatíveis com o mecanicismo, as leis do reflexo, não envolvendo variação e seleção. Em que medida, então, a seleção pelas consequências seria um modo explicativo geral se nem mesmo seria aplicável a todos os casos de comportamento? Uma interpretação alternativa é oferecida sobre a natureza e o alcance do selecionismo skinneriano.
\end{abstract}

Palavras-chave: Seleção pelas consequências; selecionismo; mecanicismo; comportamento e condicionamento reflexo; Skinner.

\begin{abstract}
The (no) place of the reflex in the causal mode selection by consequences of Skinner

Skinner in 1981 proposed a general causal mode to explain the behavior involving two basic and complementary processes: variation and selection. Sometimes selectionism is presented as a substitute mechanism inside and outside the behavioral level. However, there is a point of tension in this interpretation: the behavior/conditioning reflex. This kind of behavior and learning would be explained by laws compatible with the mechanism, the laws of reflex, not involving variation and selection. To what extent, then, selecting the consequences would be a general explanatory so even if it would apply to all cases of behavior? An alternative interpretation is offered on the nature and scope of Skinnerian selectionism.
\end{abstract}

Keywords: Selection by consequences; selectionism, mechanism; behavior and reflex conditioning; Skinner.

O artigo Selection by Consequences (Skinner, 1981) de B. F. Skinner (1904-1990) teve um grande impacto entre os analistas do comportamento. Fomentou e ainda fomenta debates, teorias e pesquisas.

A chamada "seleção por consequências" é apresentada normalmente como um modo causal (Skinner, 1981 e 1990). Um tipo especial de causalidade ambiental histórica. Tal modo causal é reconhecido em outras ciências, especialmente na biologia evolutiva de Darwin (Skinner, 1981 e 1990). No âmbito da análise do comportamento (AC) é apresentado como um modo causal capaz de explicar a origem do comportamento:

Em suma, então, o comportamento humano é o produto conjunto de a) contingências de sobrevivência responsáveis pela seleção natural das espécies, e b) contingências de reforçamento responsáveis pelos repertórios adquiridos por seus membros, incluindo c) contingências especiais mantidas por um ambiente cultural evoluído... (Skinner, 1981, p. 502, negrito acrescentado)

Posteriormente, em 1990, Skinner reafirma o papel explicativo genérico da seleção pelas consequências: "O comportamento do organismo como um todo é produto de três tipos de variação e seleção" (p. 1206, 
negrito acrescentado).

Alguns autores (como Cruz \& Cillo, 2008; Micheletto, 1995; Moxley, 1992, por exemplo) contrapõem o modo causal selecionista ao mecanicismo. Nessa interpretação, o mecanicismo é apresentado como uma perspectiva inadequada para lidar com a complexidade comportamental e o selecionismo surgiria como uma alternativa mais sofisticada e precisa. De fato, o próprio Skinner faz isso em 1981:

Como um modo causal, a seleção por conseqüências foi descoberta muito tardiamente na história da ciência - de fato, há menos de um século e meio atrás - e não é ainda completamente reconhecida ou entendida, especialmente em relação aos níveis (b) e (c). Os fatos pelos quais é responsável têm sido forçados para dentro do padrão causal da mecânica clássica, e muitos sistemas explicativos elaborados nesse processo devem ser, agora, descartados. Alguns deles têm grande prestígio e são fortemente defendidos em todos os três níveis... (p. 502, negrito acrescentado).

Tradicionalmente, dois tipos de comportamento e condicionamento são reconhecidos no âmbito da $\mathrm{AC}$ : reflexo (ou respondente) e operante. No reflexo, que pode ser condicional ou incondicional, o controle do responder é função principalmente do estímulo antecedente em uma relação S-R. As propriedades da resposta (frequência, força, duração, latência, entre outras) espelham as propriedades do próprio estímulo antecedente eliciador. As leis do reflexo (Catania, 1999; Flaherty, 1985; Keller \& Schoenfeld, 1950; Millenson, 1975) descrevem exatamente tais relações diretas.

O modo causal selecionista se apoia em dois processos fundamentais e complementares: variação e seleção. Alguma dimensão de um fenômeno variaria (características anatómicas ou fisiológicas, classes de respostas ou práticas culturais). Os eventos ambientais consequentes selecionariam alguns tipos de variação em detrimento de outros (através da sobrevivência ou de contingências de reforçamento). Gradualmente os padrões selecionados vão se tornando mais prováveis em uma determinada "população" (de organismos, de respostas ou de práticas culturais). Esse modo causal parece descrever com alguma precisão o que aconteceria no comportamento operante. Contudo, qual o lugar (ou não lugar) do reflexo nessa proposta explicativa? O fenômeno comportamental chamado de reflexo é regido por um conjunto de relações mecanicistas e não selecionistas. Para explicar o controle imediato de uma resposta reflexa ou a origem de um reflexo condicional não se recorre aos processos de variação e seleção, mas sim às variáveis ambientais que imediatamente antecedem a resposta e a uma história de associação entre eventos $\mathrm{S} / \mathrm{S}$, respectivamente. Não estamos tratando aqui simplesmente da origem do organismo que se comporta, mas da origem de um comportamento de um organismo em particular durante a ontogênese. Ou seja, dizer que a origem do organismo sensível a certos aspectos do ambiente, como no reflexo, estaria na história evolutiva de variação e seleção não é o mesmo que explicar a origem de um padrão comportamental reflexo durante a história de vida de um organismo no nível ontogenético e/ou suas variáveis de controle. Como o próprio Skinner (1981) sustenta, a base dos níveis ontogenético e cultural estaria na filogênese. Seria nela que o organismo que se comporta, e todos os mecanismos de sensibilidade ambiental e de padrões de respostas, seria(m) selecionado(s) através de variação e seleção da espécie. Mas e quanto a um padrão comportamental específico observado na ontogênese? Qual a sua origem? Sendo o selecionismo um modo causal geral do comportamento, como ele explicaria através da variação e seleção o comportamento e o condicionamento reflexo? Haveria um substituto selecionista para as leis mecanicistas do reflexo? Aparentemente não é esse o caso. Um reflexo continua sendo explicado através de relações eliciadoras incondicionais ou condicionais e de variáveis motivacionais (Flaherty, 1985). O mecanicismo mantem o seu lugar na explicação do comportamento. $^{2}$

Diante desse contexto, algumas perguntas são inevitáveis: o que significa dizer, então, que o modo causal selecionista seria uma explicação "geral"? "Geral" em relação a que exatamente se há ao menos um caso de comportamento que escapa ao seu poder explicativo? O reflexo estaria fora da seleção pelas consequências, fora da ontogênese como definida estreitamente por Skinner, excluído juntamente com o supostamente superado mecanicismo? Existe uma tensão teórica sobre o lugar (ou não lugar) do reflexo no modo causal de seleção pelas consequências de Skinner. O objetivo desse ensaio seria apresentar o problema, suas implicações e sugerir algumas interpretações.

\section{O REFLEXO: UM CONVIDADO INCONVENIENTE}

Skinner aborda o reflexo em alguns dos artigos nos quais trata da seleção pelas consequências. Em 1981, por exemplo, apresenta um tipo de pré-história e história do fenômeno comportamental:

$\mathrm{O}$ que denominamos comportamento evoluiu como um 
conjunto de funções aprofundando o intercâmbio entre organismo e ambiente. Em um mundo relativamente estável, o comportamento poderia ser parte do patrimônio genético de uma espécie assim como a digestão, a respiração ou qualquer outra função biológica. $\mathbf{O}$ envolvimento com o ambiente, contudo, impôs limitações. $O$ comportamento funcionava apropriadamente apenas sob condições relativamente similares àquelas sob as quais fora previamente selecionado. A reprodução sob uma ampla gama de condições tornou-se possível com a evolução de dois processos por meio dos quais os organismos individuais adquiriam comportamentos apropriados a novos ambientes. Por meio do condicionamento respondente (pavloviano), respostas previamente preparadas pela seleção natural poderiam ficar sob o controle de novos estímulos. Por meio do condicionamento operante, novas respostas poderiam ser fortalecidas ("reforçadas") por eventos que imediatamente as seguissem. (p. 501, negrito acrescentado).

Skinner descreve a origem do organismo que se comporta e dos próprios processos comportamentais selecionados durante a evolução das espécies. Sugere que inicialmente a presença de certos padrões regulares, os reflexos incondicionais, que teriam tido um papel importante, mas limitado, no ajuste dos organismos aos seus ambientes. Diante de um mundo mutável, um organismo preparado para responder de uma maneira específica a aspectos específicos e fixos do mundo teria óbvias dificuldades de adaptação. Sugere, então, que teriam surgido posteriormente dois processos comportamentais mais flexíveis: o condicionamento reflexo, pavloviano, e o condicionamento operante. No primeiro caso, a novidade residiria no controle antecedente, novos estímulos a controlar antigas respostas. No segundo caso, haveria a seleção de novas respostas pelas suas consequências reforçadoras. Skinner passa, então, a apresentar no artigo "Um Segundo Tipo de Seleção" e diz "O condicionamento operante é um segundo tipo de seleção por consequências" (p. 501). Se o condicionamento operante seria "O" segundo tipo de seleção pelas consequências e se a seleção natural seria o primeiro tipo, o que seria o condicionamento reflexo? Teriam surgido dois processos novos durante a evolução, mas somente o operante é tratado dentro do modo causal da seleção pelas consequências. Ambos seriam processos comportamentais selecionados como mecanismos adaptativos nos organismos durante a filogênese, mas somente o operante é reconhecido na ontogênese. A aprendizagem reflexa ou pavloviana ocorreria durante a vida de um organismo, mas como Skinner iguala ontogênese ao condicionamento operante, não haveria espaço para ela nessa proposição. $\mathrm{O}$ condicionamento reflexo seria condenado, assim, a um tipo de "limbo teórico". Curiosamente, em 1990, Skinner descreve praticamente a mesma pré-história e história do fenômeno comportamental, inclusive com a limitação dos padrões filogenéticos inflexíveis, mas ao falar da solução para tal limitação, apresenta apenas o condicionamento operante, não fazendo mais nenhuma referência ao condicionamento reflexo.

\section{SOBRE ORGANISMOS, ONTOGÊNESE E PROCES- SOS GERAIS}

Um dos pontos nebulosos no tratamento do reflexo seria confundir a origem do organismo que se comporta e todas as suas sensibilidades ambientais, o que certamente abarcará a seleção natural (o primeiro tipo de seleção), com a maneira de explicar um tipo de relação comportamental particular durante a história de vida de um organismo.

Os artigos de 1981 e de 1990 apresentam as duas informações misturadas, daí o problema. Se a questão fosse apenas sobre a origem do comportamento, qualquer que seja ele, obviamente que se chegaria ao próprio organismo que se comporta e à seleção natural. $\mathrm{O}$ modo causal do primeiro nível bastaria. Em termos de modos causais, a contraposição seria, então, entre o selecionismo e o criacionismo e não entre o selecionismo e o mecanicismo. Porém, quando Skinner estende o modo causal selecionista ao nível ontogenético ele não está simplesmente sugerindo que a origem desse outro nível deveria ser buscada na filogênese. Isso seria um truísmo. Ele afirma mais do que isso: o mecanismo causal se faria presente também nesse outro nível (assim como na cultura). O modo causal, como ele próprio explica, teria dois componentes básicos: variação e seleção. A explicação sobre a origem do "comportamento na ontogênese", não do "organismo que se comporta na ontogênese", deveria, portanto, passar pela identificação também nesse nível dos dois componentes básicos, variação e seleção. Ele faz isso muito bem ao explicar como o condicionamento operante funcionaria. Contudo, a ontogênese não é apenas condicionamento operante como ele acaba sugerindo. Há vários processos comportamentais ocorrendo durante a história de vida de um organismo. Nem todo comportamento originado na ontogênese, nem toda aprendizagem, é operante e, portanto, não poderia ser explicado universalmente por variação e seleção. $\mathrm{O}$ condicionamento respondente ou reflexo é um caso óbvio que escapa ao modo causal selecionista. As leis do reflexo são leis mecanicistas, não selecionistas, e isso não seria demérito algum para o reflexo. Elas descrevem bem o fenômeno para o qual 
foram concebidas. Como explicar a origem, durante a vida de um organismo, de uma nova resposta reflexa? Quais os mecanismos ou processos causais que atuariam durante a vida do organismo, na sua ontogênese, para construir o repertório novo? Não acharemos facilmente respostas na variação e na seleção. $\mathrm{O}$ condicionamento reflexo ou pavloviano joga por outras regras.

A seleção pelas consequências seria um modo causal envolvendo variação e seleção em uma explicação ambiental histórica. Estaria presente em diversos fenômenos orgânicos, inclusive no comportamento. Contudo, não seria o único modo causal presente nos fenômenos comportamentais. O equívoco interpretativo seria entender que o selecionismo seria um mecanismo explicativo "geral" no sentido de ser aplicável a todos os casos de comportamento. Ele seria um mecanismo explicativo "geral", não "exclusivo", porque (a) se faria presente em diferentes fenômenos orgânicos e (b) porque estaria presente em diferentes níveis de determinação (filogênese, ontogênese e cultura) de alguns tipos de comportamento. Não faria sentido, portanto, confrontar o modo explicativo selecionista ao mecanicista de maneira indiscriminada e com conotações pejorativas. Na história de explicação do fenômeno comportamental operante é possível identificar momentos em que tal fenômeno foi explicado através de uma relação estritamente $\mathrm{S} / \mathrm{R}$ (a psicologia do "estímulo resposta"), como, é bom lembrar, o próprio Skinner fez nos anos 30 (Skinner, 1938). A explicação selecionista ganhou proeminência com o passar do tempo e hoje é assumida majoritariamente como "A" explicação para o operante (Catania \& Harnard, 1988). Mas a história de explicação do comportamento operante não pode ser confundida com a história da explicação do comportamento em geral. Há muitas exceções ao selecionismo no fenômeno comportamental, como o próprio reflexo e o comportamento adjuntivo, por exemplo. Somos forçados a reconhecer que o tal modo causal selecionista não é universalmente aplicável nem mesmo dentro da ontogênese comportamental. Contudo, se entendida na forma como aqui proposta, a seleção pelas consequências se afastaria do tratamento relutante e contraditório dado ao reflexo e ganharia em consistência interna e externa.

\section{ALGUMAS CONCLUSÕES}

Para finalizar o presente ensaio, serão retomados de maneira sucinta e sistemática os pontos centrais da argumentação:
1) Uma causalidade histórica não significa uma causalidade via variação e seleção. A aprendizagem reflexa/respondente, seja por habituação/potenciação, seja por condicionamento clássico, são históricas, ocorrem na ontogênese, mas não envolvem mecanismos de variação e seleção. São explicações históricas, mas não selecionistas;

2) O conceito de ontogênese como usado por Skinner (1981 e 1990) é insuficiente para lidar com todo conjunto conhecido de fenômenos comportamentais construídos e controlados ao longo da vida de um organismo;

3) O comportamento reflexo e seus mecanismos de aprendizagem claramente violam o princípio causal selecionista, pois prescindem dos mecanismos de variação e seleção para explica-los. As leis do reflexo são leis compatíveis com a mecânica clássica;

4) $O$ modo explicativo selecionista não seria um princípio geral do comportamento no sentido de substituir qualquer outro princípio causal para esse fenômeno. Sua generalidade se daria por participar, não de maneira exclusiva, de (a) diferentes fenômenos orgânicos e (b) de diferentes níveis de determinação de alguns tipos de padrões comportamentais, especialmente no operante;

5) A crítica ao mecanicismo faz sentido no âmbito estrito das explicações operantes. A crítica parece ser dirigida às explicações do fenômeno operante que adotam a lógica mecanicista e procuram no estímulo antecedente, real ou inferido, a explicação linear para o operante. A oposição seria ao mecanicismo para lidar com o fenômeno operante e não para lidar com o comportamento em geral;

O modo causal selecionista e toda teia de relações e interpretações proposta por Skinner (1981 e 1990) mantem seu potencial heurístico. Contudo, há lacunas e derivações problemáticas que precisariam ser esclarecidas para não orientarem equivocadamente o debate (Ortega, 2006), como ocorreu com o tratamento dispensado ao comportamento/condicionamento reflexo. Espera-se ter contribuído tanto apontar uma fragilidade da proposta skinneriana, quanto para apresentar uma alternativa interpretativa mais consistente.

\section{REFERÊNCIAS}

Catania, A. C. (1999). Aprendizagem: Comportamento, linguagem e cognição. $4^{\mathrm{a}}$ edição. Porto Alegre: Artmed. 
Catania, C. A. \& Harnard, S. (1988). The selection of behavior: An operant behaviorism of B. F. Skinner. Cambridge: Cambridge University Press.

Cruz, R. N.; \& Cillo, E. N. P. (2008). Do mecanicismo ao selecionismo: Uma breve contextualização da transição do Behaviorismo Radical. Psicologia: Teoria e Pesquisa, 24(3), 375-385).

Flaherty, C. F. (1985). Animal learning and cognition. New York: McGraw-Hill, Inc.

Keller, F. S. \& Schoenfeld, W. N. (1995). Principles of psychology: A systematic text in the science of behavior. Acton, Massachusetts: Copley.

Micheletto, N. (1995). Uma questão de consequências: A elaboração da proposta metodológica de Skinner (Tese de Doutorado não publicada). Pontifícia Universidade Católica de São Paulo, São Paulo.
Millenson, J. R. (1975). Princípios de análise do comportamento. Brasília: Coordenada.

Moxley, R. A. (1992). From mechanistic to functional behaviorism. American Psychologist, 47(11), 1300-1311.

Ortega, L. A. (2006). Paralelos evolutivos en el estudio del comportamiento: Consideraciones en torno al problema del modo causal. Revista Latinoamericana de Psicología, 38 (1), 103-118.

Skinner, B. F. (1938). The behavior of organisms. New York: Appleton-Century-Crofts.

Skinner, B. F. (1981). Selection by consequences. Science, 213(4507), 501-504.

Skinner, B. F. (1990). Can psychology be a science of mind? American Psychologist, 45 (11), 1206-1210.

Notas:

1 O primeiro autor é bolsista de Produtividade do CNPq (Nível 2), a segunda e quarta autoras são bolsistas de doutorado e a terceira autora é bolsista de mestrado (todas da CAPES).

2 Para uma apresentação mais detalhada sobre o conceito de mecanicismo, ver Micheletto (1995) e Moxley (1992). 